\title{
COVID-19 and diabetes mellitus: Unraveling the hypotheses that worsen the prognosis (Review)
}

\author{
RADU ALBULESCU ${ }^{1,2^{*}}$, SIMONA OLIMPIA DIMA ${ }^{1,3^{*}}$, IOANA RALUCA FLOREA $^{1,4}$, \\ DANIELA LIXANDRU ${ }^{3,5}$, ANDREEA MADALINA SERBAN ${ }^{1,3}$, VERONICA MADALINA ASPRITOIU ${ }^{1,4}$, \\ CRISTIANA TANASE ${ }^{1,6}$, IRINEL POPESCU $^{1,3^{*}}$ and SARAH FERBER ${ }^{1,7-9}$ \\ ${ }^{1}$ ‘Nicolae Cajal' Institute, 'Titu Maiorescu’ University, 004051 Bucharest; ${ }^{2}$ National Institute \\ for Chemical-Pharmaceutical R\&D, 031299 Bucharest; ${ }^{3}$ Fundeni Clinical Institute, 022328 Bucharest; \\ ${ }^{4}$ Department of Biochemistry and Molecular Biology, Faculty of Biology, University of Bucharest, 050095 Bucharest; \\ ${ }^{5}$ Department of Biochemistry, 'Carol Davila' University of Medicine and Pharmacy, 050047 Bucharest; \\ ${ }^{6}$ Department of Biochemistry-Proteomics, 'Victor Babes' National Institute of Pathology, 050096 Bucharest, \\ Romania; ${ }^{7}$ Center for Stem Cells and Regenerative Medicine, Sheba Medical Center, \\ 5262000 Tel Hashomer; ${ }^{8}$ Orgenesis Ltd.; ${ }^{9}$ Department of Human Genetics, Tel Aviv University, \\ Sackler School of Medicine, 6997801 Tel Aviv, Israel
}

Received July 10, 2020; Accepted August 11, 2020

DOI: $10.3892 / \mathrm{etm} .2020 .9324$

\begin{abstract}
Severe acute respiratory syndrome coronavirus 2 (SARS-CoV-2) infection and the caused disease - coronavirus

Correspondence to: Professor Cristiana Tanase, 'Nicolae Cajal' Institute, 'Titu Maiorescu' University, 185 Vacaresti Road, 004051 Bucharest, Romania

E-mail: cristianatp@yahoo.com

*Contributed equally
\end{abstract}

Abbreviations: ACE, angiotensin converting enzyme; Ang, angiotensin; $\mathrm{ARB}$, angiotensin II receptor blockers; CoV, coronavirus; COVID-19, coronavirus disease 2019; CRP, C-reactive protein; DPP4, dipeptidyl peptidase-4; DPP4i, DPP4 inhibitors; ER, endoplasmic reticulum; ERGIC, endoplasmic reticulum Golgi intermediate compartment; ExoN, exoribonuclease; GLP1, glucagon-like peptide-1; GLP-1R, glucagon-like peptide-1 receptor; HCoV-229E, human coronavirus 229E; hCoV-EMC, human coronavirus-Erasmus Medical Center; HCoV-HKU1, human coronavirus HKU1; HCoV-OC43, human coronavirus OC43; HIV, human immunodeficiency virus; IFN, interferon; IL, interleukin; LDL, low-density lipoprotein; MCP-1, monocyte chemoattractant protein-1; MERS, Middle East respiratory syndrome; NADPH, nicotinamide adenine dinucleotide phosphate (reduced form); Nsps, non-structural proteins; ORF, open reading frame; PAI-1, plasminogen activator inhibitor-1; RAAS, renin-angiotensin-aldosterone system; RAS, renin-angiotensin system; SARS, severe acute respiratory syndrome; SARS-CoV, severe acute respiratory syndrome coronavirus; SARS-CoV-2, severe acute respiratory syndrome coronavirus 2; SOCS3, suppressing cytokine signaling 3; T2DM, type 2 diabetes mellitus; Th, T helper; T1DM, type 1 diabetes mellitus; TMPRRSS2, transmembrane serine protease 2 ; TNF, tumor necrosis factor

Key words: diabetes mellitus, SARS-CoV-2 infection, COVID-19, angiotensin converting enzyme 2 , hypotheses, skin complications disease 2019 (COVID-19), has affected so far $>6,000,000$ people worldwide, with variable grades of severity, and has already inflicted $>350,000$ deaths. SARS-CoV-2 infection seems severely affected by background diseases such as diabetes mellitus and its related complications, that seem to be favoring the most severe manifestations of SARS-CoV-2 and, therefore, require special attention in clinical care units. The present literature review focus on addressing several hypotheses explaining why diabetic patients could develop multi-organ failure in severe acute respiratory syndrome coronavirus (SARS-CoV) infections. Undoubtedly, as diabetes related complications are present it is expected to emphasize the severity of the COVID-19. Dermatological complications can occur and worsen in diabetic patients, and diseases such as acanthosis nigricans and psoriasis are prone to more severe manifestations of COVID-19. Approaches to treat SARS-CoV-2 infected patients, based on different solutions i.e. plasma therapy, use of antiviral compounds, development of vaccines or new therapeutic agents are ongoing.

\section{Contents}

1. Introduction

2. Interference of coronaviruses with diabetes

3. Could anti-diabetes drugs impact on disease progression?

4. Are diabetes related complications expected to worsen upon SARS-CoV-2 infection?

5. Platelet destruction in patients with diabetes and COVID-19

6. Skin complications of diabetes mellitus - relevance for SARS-CoV-2 infection

7. Treatment of SARS-CoV-2 infection

8. Conclusions 


\section{Introduction}

Coronaviruses $(\mathrm{CoV})$ are enveloped viruses with a single-stranded, positive-sense RNA genome 43 known to cause respiratory infections in humans (1). Given the phylogenetic similarity to the previously isolated severe acute respiratory syndrome coronavirus (SARS-CoV), the new virus has been named severe acute respiratory syndrome coronavirus 2 (SARS-CoV-2), and the disease it causes is called coronavirus disease 2019 (COVID-19) (2). SARS-CoV-2 was reported in people who had been exposed to a seafood market in Wuhan, China, where live animals were sold. Since then, there has been rapid spread of the virus, leading to a global pandemic of COVID-19 (3).

The COVID-19 outbreak continues to cause severe morbidity worldwide and has now infected over 6 million people worldwide, with a death toll of $>350,000$ people (https:// www.worldometers.info/coronavirus).

Worldwide data from 2020 have shown that COVID-19 is associated with different co-morbidities such as diabetes, hypertension, cardiovascular and lung diseases. Moreover, risk factors including age, male gender were associated with worse outcome in this disease (4). It is widely known that diabetes is associated with an increased risk of severe bacterial (5) and viral respiratory tract infections, including influenza and pneumonia (6). Diabetic patients with SARS-CoV-2 infection are at higher risk of experiencing a severe form of COVID-19 disease.

In the present review we are addressing several hypotheses that may explain why diabetic patients with SARS-CoV-2 infection are at higher risk of experiencing a severe form COVID-19 disease.

Diabetes by itself is unlikely to be a risk factor for SARS-CoV-2 infection. According to several studies, the prevalence of diabetes in people infected with the virus is about the same as in the general population, even slightly lower (2). However, poorly controlled blood sugar subjects are at increased risk for all infections and so there is no reason to think that this would be different for SARS-CoV-2. Moreover, any sickness that may pose a physiological stress could cause a difficult management of blood glucose levels in diabetics and especially type 1 diabetes mellitus (T1DM) patients.

Cell entry of $\mathrm{CoV}$ depends on binding of the viral spike (S) proteins to cellular receptors and on S protein priming by host cell proteases. Unravelling which cellular factors are used by SARS-CoV-2 for entry might provide insights into viral transmission and reveal therapeutic targets. SARS-CoV-2 uses the cell receptor for angiotensin converting enzyme 2 (ACE2) for cell entry and the serine protease TMPRSS2 for viral S (spike) protein priming (https://www.diabetesatlas.org/en) $(7,8)$.

\section{Interference of coronaviruses with diabetes}

More than 463 million people worldwide have diabetes (https:// www.diabetesatlas.org/en) (9). Recent studies demonstrate a high rate of mortality for people with diabetes compared to healthy subjects of similar age infected with SARS-CoV-2 (10).

The link between cell-mediated immunity, diabetes and SARS-CoV-2 infection. Diabetes is a disorder that appears after the accumulation of activated innate immune cells in metabolic tissues thus leading to a release of inflammatory cytokines, such as IL-1 $\beta$ and tumor necrosis factor (TNF)- $\alpha$ that promote insulin resistance and the $\beta$ cell destruction (11).

SARS-CoV-2 infection associated with diabetes can trigger stress conditions with higher secretion of hyperglycemic hormones (glucocorticoid and catecholamines) that can result in insulin resistance, hyperglycemia and other complications (11-13). Pancreatic $\beta$ cells, which are the only insulin producing cells in the body, could be also a target for infection and subsequent destruction as elaborated below, thus worsening the glucose homeostasis.

Respiratory viral infections including SARS-CoV-2 exhibit increased expression of interleukins (ILs), chemokines, interferon (IFN), tumor necrosis factors that were identified as cytokine storm in other studies (14). In this sense, obesity which is associated with diabetes mellitus may also worsen the outcome of SARS-CoV-2 infection, due to 'pre-activated' immune systems and resident cytokine signaling pathways such as TNF- $\alpha$, IL-1 and IL-6 (15). IL-10 that acts as a negative regulator of inflammation process, could be at lower levels in diabetic patients (16). Thus, it is critical to maintain a balance between pro- and anti-inflammatory mechanisms in order to have a balanced lung homeostasis. Studies have shown that IL-6 can sustain the activation of several cytokine pathways for days after initial immune insult (17). Also, in initial studies of COVID-19, IL-6 was a strong predictor of mortality (18).

A link between SARS-CoV-2 cell entry and the endocrine pathway of diabetes. Angiotensin converting enzyme 2(ACE2), transmembrane serine protease 2 (TMPRRSS2) and DPP4 gained interest for the clinical relevance that they exert in $\mathrm{CoV}$ infection $(2,3,8)$.

ACE22. ACE2, a transmembrane carboxypeptidase enzyme is expressed within epithelial tissues and represents the functional receptor for S1 of SARS-CoV and SARS-CoV-2 $(19,20)$. ACE2 is expressed in all tissues, with major activity in the ileum and kidney followed by respiratory system, type I and II alveolar epithelial cells in lungs, heart, endothelial cells, kidney tubular epithelium, enterocytes, and both endocrine and exocrine pancreas (19-21).

ACE2 is a key enzymatic component of the renin-angiotensin-aldosterone system (RAAS); ACE catalyzes the conversion of the prohormone, angiotensin I (AngI) to the octapeptide, angiotensin II (AngII), whereas ACE2 converts AngII to Ang 1-7. AngII, through activation of Ang II type 1a receptors induces vasoconstriction and proliferation, whereas angiotensin 1-7 stimulates vasodilatation and suppresses cell growth (13).

Low expression of ACE2 within the vasculature can promote endothelial dysfunction and inflammation and exacerbate existing atherosclerosis and diabetes $(13,22,23)$.

Both type I and type II diabetic patients have increased urinary ACE2 protein, enzymatic activity $(24,25)$ and values for urinary ACE2/Creatinine ratios that correlate positively with fasting glucose and hemoglobin A1C (17). Additionally, dysglycemia development is mechanistically linked to ACE2 and complications in subjects with diabetes remains uncertain. RNA and protein expression of ACE2 and Ang (https://www. worldometers.info/coronavirus) (1-6) is upregulated in jejunal enterocytes from the experiments with diabetic rats induced 
with streptozotocin. Whether hyperglycemia and insulin deficiency regulate ACE2 expression in human tissues has not been studied yet (26).

A relevant question to be analyzed through clinical studies is whether the virus can induce diabetes, by direct infection of pancreatic beta cells (27). Some signs of acinar pancreatic assault in COVID-19 patients was documented by increased serum elastase. The hypothesis underlying these observations is based on the fact that ACE2 has been identified in the liver and in the endocrine pancreas and is involved the development of insulin resistance $(28,29)$.

TMPRSS2. TMPRSS2, a transmembrane serine protease is highly expressed within the lung and gastrointestinal tissues, including stomach, bowel, pancreas and liver. TMPRSS2 is implicated in viral infection as it cleaves and activates influenza A and influenza B virus hemagglutinin envelope glycoproteins and also the spike protein of SARS-CoV and Middle East respiratory syndrome (MERS)-CoV, enabling virus-membrane fusion $(30,31)$.

TMPRSS2 after binding to ACE2 is involved in S protein priming and cleavage of the spike. The viral pathogenicity importance of TMPRSS2 is analyzed in studies employing TMPRSS2 inhibitors, such as camostat mesylate, which attenuates SARS-CoV-2 infection of human lung cells cultured ex vivo $(7,8)$.

Human dipeptidyl peptidase-4 (DPP4) in coronavirus infection and diabetes. DPP4 (also known as CD26) was identified as receptor for human coronavirus at Erasmus Medical Center (hCoV-EMC) (32). However, during the pandemic, specific clinical data regarding the influence of DPP4 inhibitors (DPP4i) on COVID-19 in people with diabetes are under investigation. In patients with type 2 diabetes, DPP4 is involved in insulin metabolism and inflammation by breaking the circulating glucagon-like peptide-1 (GLP1), upregulating the CD86 expression and lowering the infiltrate with macrophages (33). DPP4i, such as sitagliptin, vitagliptin, saxagliptin, alogliptin and linagliptin are currently used in therapy for patients with type 2 diabetes mellitus (T2DM). In addition to their glucose lowering effect they have been shown to decrease inflammation directly via GLP-1 dependent signaling.

A study from UK Clinical Practice Research Datalink based on a cohort study with diabetes mellitus patients found no increased risk of pneumonia in 22,435 subjects that were treated with DPP4i compared to 188,614 individuals treated with non-insulin glucose lowering agents (34). Another study had similar results also with no increased risk of infections detected in patients treated with DPP4i (35). A set of large clinical trials focused on the safety of saxagliptin, alogliptin, sitagliptin, and linagliptin in patients with diabetes mellitus at risk for cardiovascular or renal disease did not reveal clinically relevant safety issues in relation with immune or inflammatory disorders (36-39). However, in-depth investigation of the DPP4 role in SARS-CoV-2 infection is needed.

\section{Could anti-diabetes drugs impact on disease progression?}

To answer this question, we need to know if drugs, such as pioglitazone or rosiglitazone used for treatment of insulin resistance or related inflammation could impact on prognosis of patients with diabetes and SARS-CoV-2 infection (40).

Administration of insulin diminishes ACE2 expression $(41,42)$ while hypoglycemic agents such as GLP-1 agonists (liraglutide) and thiazolidinediones (pioglitazone), anti-hypertensives such as ACE inhibitors, and statins upregulate ACE2 (41,43-45).

In a study by Pfutzner et al (46), the anti-inflammatory effect induced by pioglitazone was assessed by highly sensitive C-reactive protein (CRP), level after starting therapy. It was also reported that pioglitazone induced the IL- 6 and TNF- $\alpha$ increased expression in insulin resistant individuals without manifest hyperglycaemia, and inhibits the secretions of IL- $1 \mathrm{~b}$, IL-6, and IL-8.

Another anti-inflammatory molecule that can be used in glucose-lowering therapies in subjects with diabetes mellitus and obesity is glucagon-like peptide-1 receptor (GLP-1R) agonist that reduces biomarkers of systemic inflammation in experimental studies (47). Other studies demonstrated that GLP-1R agonists attenuate pulmonary inflammation, reduces cytokine production and also preserve lung function in mice and rats with experimental lung injuries $(48,49)$. It has also been observed that circulating GLP-1 levels are increased in human subjects with sepsis and critical illness and correlated with illness severity and mortality $(50,51)$.

This effect is important for COVID-19 patients with advanced disease that had elevated levels of CRP at admission.

Metformin has anti-inflammatory proprieties and reduces circulating biomarkers of inflammation in people with diabetes mellitus (52). Metformin has also been used in patients with stable hepatitis or HIV infections and its immunomodulatory actions of metformin in the context of $\mathrm{CoV}$ infection are still to be studied $(53,54)$.

\section{Are diabetes related complications expected to worsen upon SARS-CoV-2 infection?}

Diabetes can affect many different organ systems in the body and, over time, can lead to serious complications. Complications from diabetes can be classified as microvascular or macrovascular. Microvascular complications include nervous system damage (neuropathy), renal system damage (nephropathy) and eye damage (retinopathy). Macrovascular complications include cardiovascular disease, stroke, and peripheral vascular disease. These complications of which many are related to damaged blood vessels are a significant cause of increased morbidity and mortality among people with diabetes (55). Many of the diabetes affected organs are also a target for SARS-CoV-2 infection, which may further augment the severity of the COVID-19 related disease. Moreover, all these complications are expected to worsen upon SARS-CoV-2 infection.

Effective onset of type 2 diabetes can precede clinical diagnosis by many years. In the first $10-15$ years from the diagnosis of diabetes, the incidence of diabetic nephropathy in patients with diabetes mellitus is low, after which it increases rapidly to a maximum of approximately 18 years $(56,57)$ which may explain the high prevalence of nephropathy in the diagnosis of diabetes when either a kidney transplant or a chronic dialysis treatment is needed (55). Special attention is needed on control of classic risk factors for kidney damage as recent studies show that in patients 
confirmed with COVID-19 renal disturbances are common (58). Due to acute tubular necrosis induced by sepsis, hydration, cytokine storm syndrome, rhabdomyolysis and hypoxia, renal disorders caused by COVID-19 consist of acute renal damage, and have been detected direct invasion of the virus in renal tubular cells and interstitial or glomeruli (59). Moreover, acute renal damage in COVID-19 is strongly associated with a higher level mortality and morbidity, renal evolution being an indicator for survival with $\mathrm{CoV}$ infection (59). In a study on renal function of 59 infected SARS-CoV-2 patients, $63 \%$ of patients reported proteinuria. In addition, they recorded elevated serum values for creatinine (19\%) and urea nitrogen (27\%), respectively. In addition, all patients for whom a computerized tomography was performed to scan the kidneys, had inflammation and edema of the renal parenchyma.

Possible mechanisms may be due to dehydration, which may be related to fever or decreased fluid intake having various consequences on the kidneys, leading to a reduction in glomerular filtration rate and acute kidney damage (59). Other proposed mechanisms include COVID-19 sepsis, which leads to cytokine storm syndrome. In addition, direct invasion of the virus on the renal tubular and interstitial cells or glomeruli is possible due to direct cytopathic effects on different renal cells, and could be detected due to increased ACE2 in kidneys at much higher level than in the lung $(19,60)$. The finding that SARS-CoV-2 uses ACE2 explains why the kidney cells are targeted and infected with COVID-19. This strengthens the hypothesis that renal dysfunction could accelerate the progression of inflammation started in the lungs, not just as a side effect of lung inflammation. Thus, inflammatory reactions through lung deficiencies can damage the kidney while the damage and death of renal tubular epithelial cells could also cause severe damage to the lungs and other organs through a large amount of inflammatory substances released. Above a certain critical point, the kidney-lung intersection could lead to an irreversible self-amplification storm of cytokines that quickly induces failure and death for multiple organs $(61,62)$.

Neurologic injury has been confirmed in the infection of other $\mathrm{CoV}$ infections such as in SARS-CoV and MERS-CoV, the SARS-CoV nucleic acid has been found in the cerebrospinal fluid of these patients and also in their brain tissue on autopsy $(63,64)$. One of the first reports centered on detailed neurologic manifestations of the hospitalized patients with COVID-19 had reported higher neutrophil counts, lower lymphocyte counts, higher CRP and D-dimer levels in patients with severe infection than that of patients with non-severe infection (65). In addition, multiorgan damage has been reported for patients with increased inflammation and blood coagulation. Of these patients, $14 \%$ had diabetes, $23.8 \%$ hypertension, $7 \%$ cardiac or cerebrovascular disease, and $6.1 \%$ malignancy, and $2.8 \%$ of diabetic patients had associated chronic kidney disease (65). Such aspects are illustrated in Fig. 1.

\section{Platelet destruction in patients with diabetes and COVID-19}

Higher platelet reactivity in diabetic patients is due to increased platelet functions, including an increased response to stimulation by platelet aggregation agonists, adhesion to thrombogenic surfaces and platelet aggregation (66). Oxidative stress and

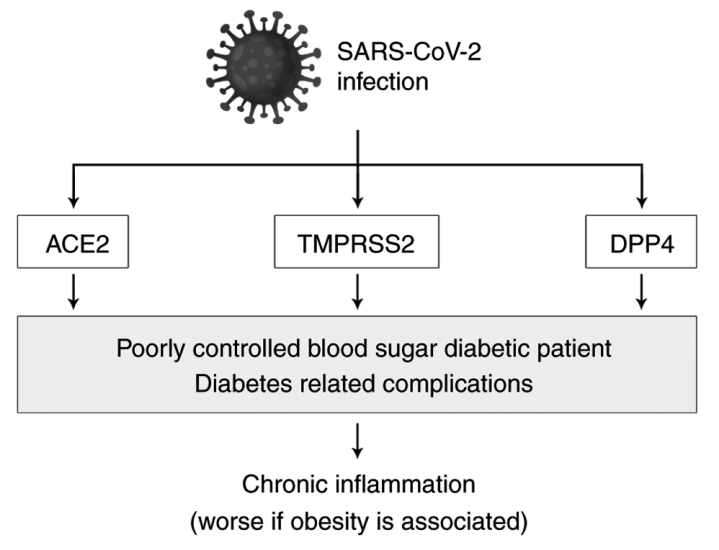

Cytokine storm syndrome (worse if COVID-19 sepsis is associated)

High platelet reactivity (worse if oxidative stress is associated) $\downarrow$

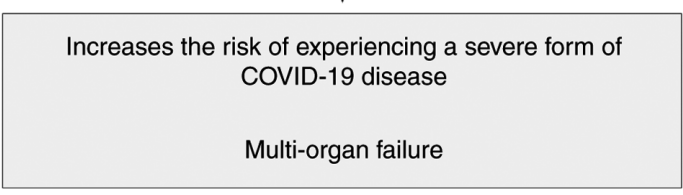

Figure 1. A hypothesis explaining severe forms of coronavirus disease 2019 (COVID-19) in diabetic patients. SARS-CoV-2, severe acute respiratory syndrome coronavirus 2; ACE2, angiotensin converting enzyme 2 ; TMPRRSS2, transmembrane serine protease 2; DPP4, dipeptidyl peptidase- 4 .

reduced antioxidant activity induced by hyperglycemia are significantly augmented in diabetic patients, subsequently leading to platelet activation and hyper-reactivity.

Increased blood coagulation could affect the severity of SARS-CoV-2 infection outcome on lung and additional critical organs function (67).

Diabetes mellitus patients have increased platelet reactivity, manifested by increased tendency to respond aggressively to particular stimuli (68). Consistent with this observation, hyperglycemia and hypertriglyceridemia contribute to increased platelet reactivity through direct effects and by promoting nonenzymatic glycation of proteins by decreasing membrane fluidity. Moreover, both decreased insulin production and insulin resistance have been shown to be a stimulator of platelet reactivity (69). Thus, both relative or absolute insulin deficiency is expected to increase platelet reactivity. If diabetes mellitus is associated with obesity, then increased oxidative stress and associated inflammation may promote the endothelial dysfunction. Oxidative stress exacerbates this effect by attenuating $\mathrm{NO}$ activity and promoting platelet activation. Inflammation favors the activation of platelets which, in turn, favors inflammation (70). Consequently, improved metabolic and glycemic control improves insulin sensitivity and maintains pancreatic $\beta$-cell function, and is likely to decrease platelet reactivity and increase the effects of antiplatelet agents. Thus, people treated with ACE2 and angiotensin 2 receptor type I (ARB) blockers, for high blood pressure that is associated with metabolic syndrome have been shown to display reduced inflammation in lungs (71). Previous pathogenic $\mathrm{CoV}$, such as SARS-CoV, have been shown to bind to their target cells through ACE2, which is expressed by 
the epithelial cells of the lungs, kidneys, intestines, pancreas and blood vessels (72). Hence, drugs that increase ACE2 expression including pioglitazone and liraglutide or ACE2 polymorphisms may further worsen virus infection prognosis (71).

Inflammatory state associated with metabolic syndrome, T2DM, and visceral obesity, plays a role also in imprinting the cluster of cardiovascular risk factors. These factors lead to an approximately 3-fold increase in the risk of coronary heart disease, stroke, and venous thromboembolism $(73,74)$ that might be among the underlying pathophysiological mechanisms contributing to the increased morbidity and mortality of COVID-19 infected people that suffer from obesity-associated diseases.

The early hypothesis was that SARS is associated with cytokine dysregulation (75-81). Subjects with SARS have high levels of pro-inflammatory cytokines and chemokines associated with $\mathrm{T}$ cell depletion, lung inflammation, and extensive lung injury (80). Increased levels of IL-6 are associated with severe disease and are found in patients with respiratory syncytial virus (RSV) infection (79). Circulating levels of IL-8, IL-1 $\beta$, and IL- 6 undergo modifications in chronic inflammatory conditions, and are critically involved in abnormal clot formation, erythrocyte pathology and platelet hyperactivation (82). Decreased cytokine levels cause an increased hypercoagulability of whole blood and affect both erythrocytes and platelets. If there was an association of the three cytokines then it caused hyperactivation and platelet spread resulted in the largest changes $(73,83-85)$.

\section{Skin complications of diabetes mellitus - relevance for SARS-CoV-2 infection}

The most recognized cutaneous manifestation in diabetes, present in $74 \%$ of obese patients with diabetes mellitus is Acanthosis nigricans (AN), a hyperpigmented velvety thickening of skin folds (86). Moreover, the presence of AN could be a good prognostic indicator for development of hyperinsulinemia in newly diagnosed diabetes mellitus with a possible genetic predisposition or increased sensitivity of the skin to increased plasma insulin levels $(87,88)$. Benign AN type 2 is linked to T2DM, initially starting insidiously with hyperpigmentation while pseudo-AN type 3 is associated with metabolic syndrome. Both underlying conditions are associated with insulin resistance (86). Among other skin manifestations that accompany diabetes is chronic psoriasis, commonly in areas of the scalp, elbows and nails, a complex interplay between an inflammatory process, polygenic skin disorders with environmental triggers such as infections (89). Recent research shows that psoriasis can increase the predisposition for the development of diabetes, strong arguments being brought in a study of 52,000 participants, which concluded that people with psoriasis have a $49-56 \%$ higher risk of development diabetes mellitus later in life (90). Furthermore, being partly immune-depressed the psoriatic patients have an increased risk for infections, and there is no data for the beneficial effect of treatment with drugs such as cyclosporine, methotrexate and anti-TNF- $\alpha$ for COVID-19 (91).

Malumperforanspedis isalong-lasting traumaaccompanied by various metabolic and infectious pathologies with a chronic ulceration in the sole of the foot (92). Malum perforans pedis is a neurovascular disease for the most part on the skin with abnormal innervations with damage infusion, the development of ulceration in the accompanied foot, loss of sensation of pain having a predominance of the appearance in the elderly and with a severe form in diabetic neuropathies (93). Some findings indicate that a common cause of morbidity and mortality in diabetic patients could be changes in the healing of skin wounds. The effects of hyperglycemia on skin keratinocytes have been proved to enhance the proliferation-differentiation balance in an in vitro model of wound healing. Indeed, a decrease in the basal glucose update rate is associated with the induction of keratinocyte differentiation. These changes have been associated with enhanced GLUT1 expression, changes in cells morphology, as well as with a low proliferation and improving $\mathrm{Ca}^{2+}$-induced keratinocyte differentiation, and it has been demonstrated that hyperglycemia and disruption of the insulin signaling pathway could be directly involved in the development of chronic complications of diabetes by affecting the use of glucose by keratinocytes, as well as by proliferating and differentiating the skin (94). However, the molecular mechanisms by which diabetes changes the structure of the skin has not been elucidated.

Currently, data in the literature on skin manifestations in COVID-19 is limited. One of the first cases that have been reported with observed cutaneous manifestations, skin rashes manifestations related with the COVID-19 disease, involving mainly the trunk, is a case with no drug intake for the previous 10 days. The observed skin manifestations are similar to those found in common viral infection (95). All of these skin complications can worsen the prognosis of people with diabetes, increasing the need for intensive care depending on severity of SARS-CoV-2 infection.

\section{Treatment of SARS-CoV-2 infection}

Recent studies explored the feasibility of convalescent plasma therapy for SARS-CoV-2 infections.

Convalescent plasma contains neutralizing antibodies that are capable of neutralizing SARS-CoV-2 from blood circulation and pulmonary tissues (96). Also, studies on COVID-19 showed that lymphocyte levels in the peripheral blood were decreased and cytokines levels in the plasma from patients with severe complication, IL-6, IL-10, TNF- $\alpha$, and granulocyte-macrophage colony-stimulating factor, were significantly higher than in those who had mild symptoms $(58,97)$.

The results of Duan et al (98) suggested that antibodies contained in convalescent plasma lowered the inflammation and overreaction of the immune system. All analyzed patients reached serum SARS-CoV-2 RNA negativity after convalescent plasma transfusion, accompanied by an increase of oxygen saturation and lymphocyte counts, and the improvement of liver function and CRP, 10 severe patients showed that only one dose of $200 \mathrm{ml}$ of convalescent plasma increased significantly or maintained the neutralizing antibodies at a high level, leading to disappearance of viremia in one week. Convalescent plasma shows a potential therapeutic effect reducing the viral load and lowering risk in the treatment of severe COVID-19 patients. Combined with other treatments, such as antiviral therapy and other supportive care, convalescent plasma improved clinical outcomes. Certain strategies used for vaccines development 
stimulate neutralizing antibodies for $\mathrm{S}$ proteins and T-cell responses which are together required in convalescence. The challenge for protective immunity against $\mathrm{CoV}$ at its start (99).

Use of $2019 \mathrm{nCoV}$ receptor binding inhibitors with high affinity for ACE-2, and angiotensin-converting enzyme inhibitors (ACE-I) or angiotensin receptor antagonists (ARA), drugs that inhibit the renin-angiotensin system (RAS) are gaining increasing popularity and could play a role in treating severe respiratory diseases $(100,101)$. Efforts are being made to develop a vaccine, which will be a major tool in the fight against COVID-19 (https://www.who.int/blueprint/priority-diseases/keyaction/list-of-candidate-vaccines-developed-against-ncov.pdf).

\section{Conclusions}

COVID-19 represents an unattended threat for health and life, having so far over $6,000,000$ infected and about 300.000 deaths. The present review brought hypotheses that should be clinically analyzed of why diabetic patients, represent a population of patients which is prone to be affected by a more severe disease manifestation of this viral infection. As the human endocrine pancreas expresses ACE-2, the coronavirus might enter islets and cause acute $\beta$-cell dysfunction, leading to acute hyperglycemia and transient T2DM. Moreover, ACE-2 activity levels could be enhanced in diabetic patients making the SARS-CoV infections more efficient also in peripheral, non-pancreatic tissues. This may explain why diabetes mellitus can contribute mechanistically to multi-organ failure in SARS-CoV infections. Some skin complications can worsen the prognosis of people with diabetes, increasing the need for intensive care depending on severity of SARS-CoV-2 infection. On the other hand, some of the drugs used to ameliorate diabetes mellitus and its complications, can also affect rate of SARS-CoV infections, such as GLP-1 analogs and others.

\section{Acknowledgements}

Not applicable.

\section{Funding}

This study was supported by the Research Grant: Dia-Cure P_37_794, POC-A. 1- A.1.1.4-E-2015 (2016-2020) and the projects PN 19-29.01.04 and P19-41-05-01.

\section{Availability of data and materials}

The datasets used and/or analyzed during the current study are available from the corresponding author on reasonable request.

\section{Authors' contributions}

RA, SOD, IRF, DL, AMS, VMA, CT, IP and SF contributed to the data acquisition, manuscript drafting and critical revision of the manuscript for important intellectual content. All authors read and approved the final manuscript.

\section{Ethics approval and consent to participate}

Not applicable.

\section{Patient consent for publication}

Not applicable.

\section{Competing interests}

The authors declare that they have no competing interests.

\section{References}

1. Cui J, Li F and Shi ZL: Origin and evolution of pathogenic coronaviruses. Nat Rev Microbiol 17: 181-192, 2019.

2. Hussain A, Bhowmik B and do Vale Moreira NC: COVID-19 and diabetes: Knowledge in progress. Diabetes Res Clin Pract 162: $108142,2020$.

3. Gandhi RT, Lynch JB and Del Rio C: Mild or moderate covid-19. N Engl J Med: Apr 24, 2020 (Epub ahead of print). doi: 10.1056/ NEJMcp2009249.

4. Ryan PM and Caplice NM: Is adipose tissue a reservoir for viral spread, immune activation and cytokine amplification in Coronavirus disease 2019. Obesity (Silver Spring) 28: 1191-1194, 2020.

5. Hodgson K, Morris J, Bridson T, Govan B, Rush Cand Ketheesan N: Immunological mechanisms contributing to the double burden of diabetes and intracellular bacterial infections. Immunology 144: 171-185, 2015.

6. Allard R, Leclerc P, Tremblay C and Tannenbaum TN: Diabetes and the severity of pandemic influenza A (H1N1) infection. Diabetes Care 33: 1491-1493, 2010.

7. Hoffmann M, Kleine-Weber H, Schroeder S, Kruger N, Herrler T, Erichsen S, Schiergens TS, Herrler G, Wu NH, Nitsche A, et al: SARS-CoV-2 cell entry depends on ACE2 and TMPRSS2 and is blocked by a clinically proven protease inhibitor. Cell 181: 271-280.e8, 2020.

8. Docea AO, Tsatsakis A, Albulescu D, Cristea O, Zlatian O, Vinceti M, Moschos SA, Tsoukalas D, Goumenou M, Drakoulis N, et al: A new threat from an old enemy: Reemergence of coronavirus (Review). Int J Mol Med 45: 1631-1643, 2020.

9. Saeedi P,Petersohn I, Salpea P, Malanda B, Karuranga S, Unwin N, Colagiuri S, Guariguata L, Motala AA, Ogurtsova K, et al: Global and regional diabetes prevalence estimates for 2019 and projections for 2030 and 2045: Results from the International Diabetes Federation Diabetes Atlas, 9(th) edition. Diabetes Res Clin Pract 157: 107843, 2019.

10. Guo W, Li M, Dong Y, Zhou H, Zhang Z, Tian C, Qin R, Wang H, Shen Y, Du K, et al: Diabetes is a risk factor for the progression and prognosis of COVID-19. Diabetes Metab Res Rev: Mar 31, 2020 (Epub ahead of print). doi: 10.1002/dmrr.3319.

11. Odegaard JI and Chawla A: Connecting type 1 and type 2 diabetes through innate immunity. Cold Spring Harb Perspect Med 2: a007724, 2012.

12. Wang A, Zhao W, Xu Z and Gu J: Timely blood glucose management for the outbreak of 2019 novel coronavirus disease (COVID-19) is urgently needed. Diabetes Res Clin Pract 162: 108118,2020

13. Lovren F, Pan Y, Quan A, Teoh H, Wang G, Shukla PC, Levitt KS, Oudit GY,Al-Omran M, Stewart DJ, et al: Angiotensin converting enzyme-2 confers endothelial protection and attenuates atherosclerosis. Am J Physiol Heart Circ Physiol 295: H1377-H1384, 2008.

14. Tisoncik JR, Korth MJ, Simmons CP, Farrar J, Martin TR and Katze MG: Into the eye of the cytokine storm. Microbiol Mol Biol Rev 76: 16-32, 2012.

15. Kern L, Mittenbuhler MJ, Vesting AJ, Ostermann AL, Wunderlich CM and Wunderlich FT: Obesity-induced TNFa and IL-6 signaling: The missing link between obesity and inflammation-driven liver and colorectal cancers. Cancers (Basel) 11: 24, 2018.

16. Park WY, Goodman RB, Steinberg KP, Ruzinski JT, Radella F, II, Park DR, Pugin J, Skerrett SJ, Hudson LD and Martin TR: Cytokine balance in the lungs of patients with acute respiratory distress syndrome. Am J Respir Crit Care Med 164: 1896-1903, 2001.

17. Yiu HH, Graham AL and Stengel RF: Dynamics of a cytokine storm. PLoS One 7: e45027, 2012. 
18. Ruan Q, Yang K, Wang W, Jiang L and Song J: Clinical predictors of mortality due to COVID-19 based on an analysis of data of 150 patients from Wuhan, China. Intensive Care Med 46: 846-848, 2020.

19. Li W, Moore MJ, Vasilieva N, Sui J, Wong SK, Berne MA, Somasundaran M, Sullivan JL, Luzuriaga K, Greenough TC, et al: Angiotensin-converting enzyme 2 is a functional receptor for the SARS coronavirus. Nature 426: 450-454, 2003.

20. Raj VS, Mou H, Smits SL, Dekkers DH, Muller MA, Dijkman R, Muth D, Demmers JA, Zaki A, Fouchier RA, et al: Dipeptidyl peptidase 4 is a functional receptor for the emerging human coronavirus-EMC. Nature 495: 251-254, 2013.

21. Liu F, Long X, Zhang B, Zhang W, Chen X and Zhang Z: ACE2 expression in pancreas may cause pancreatic damage after SARS-CoV-2 infection. Clin Gastroenterol Hepatol 18: 2128-2130.e2, 2020.

22. Yousif MH, Dhaunsi GS, Makki BM, Qabazard BA, Akhtar S and Benter IF: Characterization of Angiotensin-(1-7) effects on the cardiovascular system in an experimental model of type-1 diabetes. Pharmacol Res 66: 269-275, 2012.

23. Zhang C, Zhao YX, Zhang YH, Zhu L, Deng BP, Zhou ZL, Li SY, Lu XT, Song LL, Lei XM, et al: Angiotensin-converting enzyme 2 attenuates atherosclerotic lesions by targeting vascular cells. Proc Natl Acad Sci USA 107: 15886-15891, 2010.

24. Burns KD, Lytvyn Y, Mahmud FH, Daneman D, Deda L, Dunger DB, Deanfield J, Dalton RN, Elia Y, Har R, et al: The relationship between urinary renin-angiotensin system markers, renal function, and blood pressure in adolescents with type 1 diabetes. Am J Physiol Renal Physiol 312: F335-F342, 2017.

25. Gutta S, Grobe N, Kumbaji M, Osman H, Saklayen M, Li G and Elased KM: Increased urinary angiotensin converting enzyme 2 and neprilysin in patients with type 2 diabetes. Am J Physiol Renal Physiol 315: F263-F274, 2018.

26. Wong TP, Ho KY, Ng EK, Debnam ES and Leung PS Upregulation of ACE2-ANG-(1-7)-Mas axis in jejunal enterocytes of type 1 diabetic rats: Implications for glucose transport. Am J Physiol Endocrinol Metab 303: E669-E681, 2012.

27. Bornstein SR, Rubino F, Khunti K, Mingrone G, Hopkins D, Birkenfeld AL, Boehm B, Amiel S, Holt RI, Skyler JS, et al: Practical recommendations for the management of diabetes in patients with COVID-19. Lancet Diabetes Endocrinol 8: 546-550, 2020 .

28. Bindom SM and Lazartigues E: The sweeter side of ACE2: Physiological evidence for a role in diabetes. Mol Cell Endocrinol 302: 193-202, 2009.

29. Maddaloni E and Buzzetti R: Covid-19 and diabetes mellitus: Unveiling the interaction of two pandemics. Diabetes Metab Res Rev: Mar 31, 2020 (Epub ahead of print). doi: 10.1002/dmrr.3321.

30. Iwata-Yoshikawa N, Okamura T, Shimizu Y, Hasegawa H Takeda M and Nagata N: TMPRSS2 contributes to virus spread and immunopathology in the airways of murine models after coronavirus infection. J Virol 93: e01815-e1818, 2019.

31. Limburg H, Harbig A, Bestle D, Stein DA, Moulton HM, Jaeger J, Janga H, Hardes K, Koepke J, Schulte L, et al: TMPRSS2 is the major activating protease of influenza a virus in primary human airway cells and influenza $B$ virus in human type ii pneumocytes. J Virol 93: e00649-19, 2019.

32. Iacobellis G: COVID-19 and diabetes: Can DPP4 inhibition play a role? Diabetes Res Clin Pract 162: 108125, 2020.

33. Ceriello A, Stoian AP and Rizzo M: COVID-19 and diabetes management: What should be considered? Diabetes Res Clin Pract 163: 108151, 2020.

34. van der Zanden R, de Vries F, Lalmohamed A, Driessen JH, de Boer A, Rohde G, Neef C and den Heijer C: Use of dipeptidyl-peptidase- 4 inhibitors and the risk of pneumonia: A population-based cohort study. PLoS One 10: e0139367, 2015.

35. Gooßen K and Gräber S: Longer term safety of dipeptidyl peptidase- 4 inhibitors in patients with type 2 diabetes mellitus: Systematic review and meta-analysis. Diabetes Obes Metab 14: 1061-1072, 2012

36. Green JB, Bethel MA, Armstrong PW, Buse JB, Engel SS, Garg J, Josse R, Kaufman KD, Koglin J, Korn S, et al: Effect of sitagliptin on cardiovascular outcomes in type 2 diabetes. N Engl J Med 373: 232-242, 2015.

37. Rosenstock J, Perkovic V, Johansen OE, Cooper ME, Kahn SE, Marx N, Alexander JH, Pencina M, Toto RD, Wanner C, et al: Effect of Linagliptin vs placebo on major cardiovascular events in adults with type 2 diabetes and high cardiovascular and renal risk: The CARMELINA Randomized Clinical Trial. JAMA 321: 69-79, 2019.
38. Scirica BM, Bhatt DL, Braunwald E, Steg PG, Davidson J, Hirshberg B, Ohman P, Frederich R, Wiviott SD, Hoffman EB, et al: Saxagliptin and cardiovascular outcomes in patients with type 2 diabetes mellitus. N Engl J Med 369: 1317-1326, 2013.

39. White WB, Cannon CP, Heller SR, Nissen SE, Bergenstal RM, Bakris GL, Perez AT, Fleck PR, Mehta CR, Kupfer S, et al: Alogliptin after acute coronary syndrome in patients with type 2 diabetes. N Engl J Med 369: 1327-1335, 2013.

40. Carboni E and Carta AR: Can pioglitazone be potentially useful therapeutically in treating patients with COVID-19? Med Hypotheses 140: 109776, 2020.

41. Ferrario CM, Jessup J, Chappell MC, Averill DB, Brosnihan KB, Tallant EA, Diz DI and Gallagher PE: Effect of angiotensinconverting enzyme inhibition and angiotensin II receptor blockers on cardiac angiotensin-converting enzyme 2. Circulation 111: 2605-2610, 2005

42. Wysocki J, Ye M, Soler MJ, Gurley SB, Xiao HD, Bernstein KE, Coffman TM, Chen S and Batlle D: ACE and ACE2 activity in diabetic mice. Diabetes 55: 2132-2139, 2006.

43. Romani-Perez M, Outeirino-Iglesias V, Moya CM, Santisteban P, Gonzalez-Matias LC, Vigo E and Mallo F: Activation of the GLP-1 Receptor by liraglutide increases ACE2 expression, reversing right ventricle hypertrophy, and improving the production of SP-A and SP-B in the lungs of type 1 diabetes rats. Endocrinology 156: 3559-3569, 2015.

44. Wosten-van Asperen RM, Lutter R, Specht PA, Moll GN, van Woensel JB, van der Loos CM, van Goor H, Kamilic J, Florquin S and Bos AP: Acute respiratory distress syndrome leads to reduced ratio of ACE/ACE2 activities and is prevented by angiotensin-(1-7) or an angiotensin II receptor antagonist. J Pathol 225: 618-627, 2011.

45. Zhang W, Xu YZ, Liu B, Wu R, Yang YY, Xiao XQ and Zhang X: Pioglitazone upregulates angiotensin converting enzyme 2 expression in insulin-sensitive tissues in rats with high-fat diet-induced nonalcoholic steatohepatitis. ScientificWorldJournal 2014: 603409, 2014.

46. Pfutzner A, Schondorf T, Hanefeld M and Forst T: High-sensitivity $\mathrm{C}$-reactive protein predicts cardiovascular risk in diabetic and nondiabetic patients: Effects of insulin-sensitizing treatment with pioglitazone. J Diabetes Sci Technol 4: 706-716, 2010.

47. Drucker DJ: Mechanisms of action and therapeutic application of glucagon-like peptide-1. Cell Meta 27: 740-756, 2018.

48. Toki S, Goleniewska K, Reiss S, Zhang J, Bloodworth MH, Stier MT, Zhou W, Newcomb DC, Ware LB, Stanwood GD, et al: Glucagon-like peptide 1 signaling inhibits allergen-induced lung IL-33 release and reduces group 2 innate lymphoid cell cytokine production in vivo. J Allergy Clin Immunol 142: 1515-1528 e8, 2018.

49. Viby NE, Isidor MS, Buggeskov KB, Poulsen SS, Hansen JB and Kissow H: Glucagon-like peptide-1 (GLP-1) reduces mortality and improves lung function in a model of experimental obstructive lung disease in female mice. Endocrinology 154: 4503-4511, 2013.

50. Kahles F, Meyer C, Mollmann J, Diebold S, Findeisen HM, Lebherz C, Trautwein C, Koch A, Tacke F, Marx N and Lehrke M: GLP-1 secretion is increased by inflammatory stimuli in an IL-6-dependent manner, leading to hyperinsulinemia and blood glucose lowering. Diabetes 63: 3221-3229, 2014.

51. Lebherz C, Schlieper G, Mollmann J, Kahles F, Schwarz M, Brunsing J, Dimkovic N, Koch A, Trautwein C, Flöge J, et al: GLP-1 levels predict mortality in patients with critical illness as well as end-stage renal disease. Am J Med 130: 833-841.e3, 2017.

52. Cameron AR, Morrison VL, Levin D, Mohan M, Forteath C, Beall C, McNeilly AD, Balfour DJ, Savinko T, Fagerholm SC, et al: Anti-inflammatory effects of metformin irrespective of diabetes status. Circ Res 119: 652-665, 2016.

53. Agarwal D, Schmader KE, Kossenkov AV, Doyle S, Kurupati R and Ertl HCJ: Immune response to influenza vaccination in the elderly is altered by chronic medication use. Immun Ageing 15: 19, 2018.

54. Saenwongsa W, Nithichanon A, Chittaganpitch M, Buayai K, Kewcharoenwong C, Thumrongwilainet B, Butta P, Palaga T, Takahashi Y, et al: Metformin-induced suppression of IFN-alpha via mTORC1 signalling following seasonal vaccination is associated with impaired antibody responses in type 2 diabetes. Sci Rep 10: 3229, 2020.

55. Deshpande AD, Harris-Hayes M and Schootman M: Epidemiology of diabetes and diabetes-related complications. Phys Ther 88: 1254-1264, 2008.

56. Bojestig M, Arnqvist HJ, Hermansson G, Karlberg BE and Ludvigsson J: Declining incidence of nephropathy in insulindependent diabetes mellitus. N Engl J Med 330: 15-18, 1994. 
57. Harris MI, Klein R, Welborn TA and Knuiman MW: Onset of NIDDM occurs at least 4-7 yr before clinical diagnosis. Diabetes Care 15: 815-819, 1992.

58. Huang C, Wang Y, Li X, Ren L, Zhao J, Hu Y, Zhang L, Fan G, Xu J, Gu X, et al: Clinical features of patients infected with 2019 novel coronavirus in Wuhan, China. Lancet 395: 497-506, 2020.

59. Valizadeh RBA, Mirzazadeh A and Bhaskar LVKS: Coronavirus-nephropathy; renal involvement in COVID-19. J Renal Inj Prev 9: e18, 2020

60.Zhou P, Yang XL, Wang XG, Hu B, Zhang L, Zhang W, Si HR Zhu Y, Li B, Huang CL, et al: A pneumonia outbreak associated with a new coronavirus of probable bat origin. Nature 579: 270-273, 2020.

61. Faubel S and Edelstein CL: Mechanisms and mediators of lung injury after acute kidney injury. Nat Rev Nephrol 12: 48-60, 2016.

62. Wang $\mathrm{H}$ and $\mathrm{Ma} \mathrm{S}$ : The cytokine storm and factors determining the sequence and severity of organ dysfunction in multiple organ dysfunction syndrome. Am J Emerg Med 26: 711-715, 2008.

63. Arabi YM, Balkhy HH, Hayden FG, Bouchama A, Luke T, Baillie JK, Al-Omari A, Hajeer AH, Senga M, Denison MR, et al: Middle East respiratory syndrome. N Engl J Med 376: 584-594, 2017.

64. Desforges M, Le Coupanec A, Brison E, Meessen-Pinard M and Talbot PJ: Human respiratory coronaviruses: Neuroinvasive, neurotropic and potentially neurovirulent pathogens. Virologie (Montrouge) 18: 5-16, 2014.

65. Mao L, Jin H, Wang M, Hu Y, Chen S, He Q, Chang J, Hong C, Zhou Y, Wang D, et al: Neurologic manifestations of hospitalized patients with coronavirus disease 2019 in Wuhan, China JAMA Neurol 77: 1-9, 2020.

66. Maiocchi S, Alwis I, Wu MCL, Yuan Y and Jackson SP: Thromboinflammatory functions of platelets in ischemia-reperfusion injury and its dysregulation in diabetes. Semin Thromb Hemost 44: 102-113, 2018

67. Demirtunc R, Duman D, Basar M, Bilgi M, Teomete M and Garip T: The relationship between glycemic control and platelet activity in type 2 diabetes mellitus. J Diabetes Complications 23 $89-94,2009$.

68. Angiolillo DJ, Fernandez-Ortiz A, Bernardo E, Ramirez C, Sabate M, Jimenez-Quevedo P, Hernandez R, Moreno R, Escaned J, Alfonso F, et al: Platelet function profiles in patients with type 2 diabetes and coronary artery disease on combined aspirin and clopidogrel treatment. Diabetes 54: 2430-2435, 2005.

69. Vaidyula VR, Boden G and Rao AK: Platelet and monocyte activation by hyperglycemia and hyperinsulinemia in healthy subjects. Platelets 17: 577-585, 2006.

70. Schneider DJ: Factors contributing to increased platelet reactivity in people with diabetes. Diabetes Care 32: 525-527, 2009.

71. Fang L, Karakiulakis G and Roth M: Are patients with hypertension and diabetes mellitus at increased risk for COVID-19 infection? Lancet Respir Med 8: e21, 2020.

72. Wan Y, Shang J, Graham R, Baric RS and Li F: Receptor recognition by the novel coronavirus from Wuhan: An analysis based on decade-long structural studies of SARS coronavirus. J Virol 94: e00127-e00220, 2020.

73. Hubert HB, Feinleib M, McNamara PM and Castelli WP Obesity as an independent risk factor for cardiovascular disease: A 26-year follow-up of participants in the Framingham Heart Study. Circulation 67: 968-977, 1983.

74. Tsai AW, Cushman M, Rosamond WD, Heckbert SR, Polak JF and Folsom AR: Cardiovascular risk factors and venous thromboembolism incidence: The longitudinal investigation of thromboembolism etiology. Arch Intern Med 162: 1182-1189, 2002.

75. Nicholls JM, Poon LL, Lee KC, Ng WF, Lai ST, Leung CY, Chu CM, Hui PK, Mak KL, Lim W, et al: Lung pathology of fatal severe acute respiratory syndrome. Lancet 361: 1773-1778, 2003.

76. Chen J and Subbarao K: The immunobiology of SARS ${ }^{*}$. Annu Rev Immunol 25: 443-472, 2007.

77. Kalliolias GD and Ivashkiv LB: Overview of the biology of type I interferons. Arthritis Res Ther 12 (Suppl 1): S1, 2010.

78. Law HK, Cheung CY, Ng HY, Sia SF, Chan YO, Luk W, Nicholls JM, Peiris JS and Lau YL: Chemokine up-regulation in SARS-coronavirus-infected, monocyte-derived human dendritic cells. Blood 106: 2366-2374, 2005.
79. Okabayashi T, Kariwa H, Yokota S, Iki S, Indoh T, Yokosawa N, Takashima I, Tsutsumi $\mathrm{H}$ and Fujii N: Cytokine regulation in SARS coronavirus infection compared to other respiratory virus infections. J Med Virol 78: 417-424, 2006.

80. Zhang Y, Li J, Zhan Y, Wu L, Yu X, Zhang W, Ye L, Xu S, Sun R, Wang Y and Lou J: Analysis of serum cytokines in patients with severe acute respiratory syndrome. Infect Immun 72: 4410-4415, 2004.

81. Lo AW, Tang NL and To KF: How the SARS coronavirus causes disease: Host or organism? J Pathol 208: 142-151, 2006

82. Choi G, Schultz MJ, Levi M and van der Poll T: The relationship between inflammation and the coagulation system. Swiss Med Wkly 136: 139-144, 2006.

83. Bester J and Pretorius E: Effects of IL-1 $\beta$, IL-6 and IL-8 on erythrocytes, platelets and clot viscoelasticity. Sci Rep 6: 32188, 2016.

84. Gupta R, Ghosh A, Singh AK and Misra A: Clinical considerations for patients with diabetes in times of COVID-19 epidemic Diabetes Metab Syndr 14: 211-212, 2020.

85. Lixandru D BE, Vîrgolici B, Vîrgolici H, Alexandru P, Băcanu ME, Gagniuc P, Ionescu-Tîrgoviste C and Serafinceanu C: Changes in the serum proinflammatory cytokines in patients with elevated HOMA-IR and type 2 diabetes mellitus. Farmacia 63: 132-139, 2015

86. Kalus AA CA and Oleraud JE: Diabetes mellitus and other endocrine diseases. In: Fitzpatrick's Dermatology in General Medicine. Goldsmith LA, Katz S, Gilchrest BA, Paller AS, Leffel DJ and Wolff K (eds.). McGrawHill, New York, NY, 2012.

87. Popa ML, Popa AC, Tanase C and Gheorghisan-Galateanu AA Acanthosis nigricans: To be or not to be afraid. Oncol Lett 17 4133-4138, 2019.

88. Hud JA Jr, Cohen JB, Wagner JM and Cruz PD Jr: Prevalence and significance of acanthosis nigricans in an adult obese population. Arch Dermatol 128: 941-944, 1992.

89. Duff M, Demidova O, Blackburn S and Shubrook J: Cutaneous manifestations of diabetes mellitus. Clin Diabetes 33: 40-48, 2015.

90. Khalid U,Hansen PR, Gislason GH, Lindhardsen J, Kristensen SL, Winther SA, Skov L, Torp-Pedersen C and Ahlehoff O: Psoriasis and new-onset diabetes: A Danish nationwide cohort study. Diabetes Care 36: 2402-2407, 2013.

91. Conforti C, Giuffrida R, Dianzani C, Di Meo N and Zalaudek I COVID-19 and psoriasis: Is it time to limit treatment with immunosuppressants? A call for action. Dermatol Ther: Mar 11, 2020 (Epub ahead of print). doi: 10.1111/dth.13298.

92. Tesch M: Spinal claudication and malum perforans pedis. Late sequela of ankylosing spondylitis (Bechterew disease) with cystic lumbosacral arachnopathy. Der Nervenarzt 65: 874-877, 1994 (In German).

93. Begolli Gerqari A, Ferizi M, Halimi S, Aferdita Daka A Hapciu S, Begolli I, Begolli M and Gerqari I: Malum perforans pedis - case report. Sci J Clin Med 5: 29-31, 2016.

94. Spravchikov N, Sizyakov G, Gartsbein M, Accili D, Tennenbaum T and Wertheimer E: Glucose effects on skin keratinocytes: Implications for diabetes skin complications. Diabetes 50: 1627-1635, 2001.

95. Recalcati S: Cutaneous manifestations in COVID-19: A first perspective. J Eur Acad Dermatol Venereol 35: e212-e213, 2020.

96. Marano G, Vaglio S, Pupella S, Facco G, Catalano L, Liumbruno GM and Grazzini G: Convalescent plasma: New evidence for an old therapeutic tool? Blood Transfus 14: 152-157, 2016.

97. Chen N, Zhou M, Dong X, Qu J, Gong F, Han Y, Qiu Y, Wang J, Liu Y, Wei Y, et al: Epidemiological and clinical characteristics of 99 cases of 2019 novel coronavirus pneumonia in Wuhan, China: A descriptive study. Lancet 395: 507-513, 2020.

98. Duan K, Liu B, Li C, Zhang H, Yu T, Qu J, Zhou M, Chen L, Meng $\mathrm{S}, \mathrm{Hu} \mathrm{Y}$, et al: Effectiveness of convalescent plasma therapy in severe COVID-19 patients. Proc Natl Acad Sci USA 117: 9490-9496, 2020.

99. Calina D, Docea AO, Petrakis D, Egorov AM,Ishmukhametov AA, Gabibov AG, Shtilman MI, Kostoff R, Carvalho F, Vinceti M, et al: Towards effective COVID-19 vaccines: Updates, perspectives and challenges (Review). Int J Mol Med 46: 3-16, 2020.

100. Kickbusch I and Leung G: Response to the emerging novel coronavirus outbreak. BMJ 368: m406, 2020.

101. Sun ML, Yang JM, Sun YP and Su GH: Inhibitors of RAS might be a good choice for the therapy of COVID-19 pneumonia. Zhonghua Jie He He Hu Xi Za Zhi 43: 219-222, 2020 (In Chinese). 